\title{
Efektivitas E-Modul Pembelajaran Sosiologi Berbasis Anyflip dalam Meningkatkan Penguasaan Materi Siswa Kelas XI di SMA
}

\author{
Rizka Anggelina ${ }^{1}$, Ike Sylvia ${ }^{2}$ \\ ${ }_{1,2}^{1}$ Universitas Negeri Padang \\ Email: riskaangelina594@gmail.com, $\underline{\text { ikesylvia@fis.unp.ac.id }}$
}

\begin{abstract}
Abstrak
Pendidikan merupakan suatu kebutuhan yang harus dipenuhi bagi umat manusia untuk bisa bertahan (survive) dalam menghadapi tantangan dan masalah yang ada di dalam kehidupan. Pada abad 21 perkembangan ilmu pengetahuan dan teknologi sangat berkembang dan berpengaruh untuk mendorong digitalisasi dalam pembelajaran. Untuk menyikapi hal tersebut, pemanfaatan sumber belajar perlu mengintegrasikan teknologi moderen agar dapat memacu berkembangnya kompetensi abad 21 siswa. Tujuan dari penelitian ini adalah untuk menghasilkan sumber belajar berupa e-modul pada pembelajaran sosiologi berbasis anyflip yang dapat meningkatkan penguasaan materi siswa serta dapat digunakan pada pembelajaran sosiologi Kelas XI IPS SMA. Penelitian ini menggunakan metode eksperimen dengan rancangan penelitian one group prettest-posttest design. Sampel dalam penelitian ini adalah 31 orang siswa kelas XI IPS 2 di SMA Negeri 6 Merangin. Uji analisis data menggunakan uji t untuk data berhubungan. Hasil dari penelitian ini menunjukan e-modul pada pembelajaran sosiologi berbasis anyflip ini terbukti efektif sesuai dengan hasil pengujian yang empiris.
\end{abstract}

Kata Kunci: E-modul, Efektivitas, Pembelajaran Sosiologi

Abstract

Education is a need that must be met for human beings to survive in the face of challenges and problems that exist in life. In the 21st century, the development of science and technology is significantly developed and influential in encouraging digitalization in learning. To address this, the use of learning resources needs to integrate modern technology to spur the development of the 21st-century competence of students. The purpose of this research is to produce learning resources in the form of e-modules in any flipbased sociology learning that can improve students' mastery of the material and can be used in sociology learning for Class XI Social Sciences in SMA. This study uses an experimental method with a one-group pretest-posttest research design. The sample in this study were 31 students of class XI IPS 2 at SMA Negeri 6 Merangin. Test data analysis using t-test for related data. The results of this study show that the e-module in any flip-based sociology learning is proven to be effective according to the results of empirical testing.

Keywords: E-module, Effectiveness, Learning Sociology

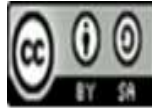

\begin{tabular}{l|l|l|} 
Received: July 19, 2021 & Revised: September 28, 2021 & Accepted: November 30, 2021
\end{tabular}

Jurnal Sikola: Jurnal Kajian Pendidikan dan Pembelajaran Vol. 3, No. 2, Th. 2021 


\section{Pendahuluan}

Pada saat ini perubahan ilmu pengetahuan dan teknologi sangat berpengaruh untuk mewujudkan perkembangan inovasi sains dan pembelajaran. Ilmu pengetahuan menjadi sangat mudah untuk digunakan dimanapun dan kapanpun. Perkembangan zaman ini tentunya berdampak pada pelaksanaan pembelajaran, guru diharapkan untuk mampu menerapkan teknologi informasi dan komunikasi secara sistematis, terintegrasi, dan efektif sesuai dengan keadaan dan kondisi termasuk untuk mampu memanfaatkan teknologi sebagai sumber belajar (Solihudin JH, 2018).

Sumber belajar merupakan segala jenis media, benda, data, fakta, ide, orang, dan lain-lain yang dapat mempermudah terjadinya proses belajar bagi siswa. Penggunaan sumber pada pembelajaran sebaiknya disesuikan dengan kebutuhan siswa untuk menyikapi kemajuan teknologi moderen pada saat sekarang ini, dan dimanfaatkan oleh guru agar dijadikan acuan sumber pembelajaran yang baik (Sudarsana, 2018). Berdasarkan peraturan pemerintah Nomor 17 Tahun 2010 dinyatakan bahwa dalam menyelenggarakan dan mengelola pendidikan, satuan atau program pendidikan berbasis teknologi informasi dan komunikasi, pembelajaran saat ini harusnya sudah menunjukkan penggunaan pada sumber pembelajaran berbasis teknologi informasi menjadi suatu kebutuhan sekaligus tuntutan di masa era globalisasi sehingga dapat menciptakan kualitas dan mutu manusia yang tidak hanya bergantung melalui transfer ilmu secara verbal (Arsal, Danial, \& Hala, 2019).

Siswa dan guru harus mampu memanfaatkan sumber belajar dalam pembelajaran. Sumber belajar dapat disusun variatif dan menarik sehingga dapat digunakan sebagai penunjang kegiatan belajar siswa secara mandiri. Pembelajaran mandiri perlu didesain khusus agar mempertimbangkan penggunaan berbagai aspek dan sumber pembelajaran baik yang tersedia secara offline ataupun berbasis teknologi. Namun dewasa ini tidak dipungkiri bahwa guru masih memiliki keterbatasan dalam mengembangkan sumber belajar dengan mengintegrasikan teknologi didalamnya, salah satunya dipengaruhi oleh begitu padatnya jam mengajar guru di sekolah sehingga menyebabkan guru tidak sempat untuk mempersiapkan bahan ajar yang terbaru.

Fakta terkait hal tersebut di atas dijumpai pada saat dilakukan wawancara dengan guru sosiologi kelas XI IPS di SMA Negeri 6 Merangin. Guru sosiologi mengeluhkan bahwa ia tidak mempunyai cukup waktu dalam mengembangkan sumber belajar yang dapat menciptakan terjadinya proses belajar secara mandiri dalam diri siswa dan terintegrasi dengan teknologi. Menurutnya untuk pengadaan sumber belajar mandiri sangat diperlukan, dikarenakan siswa kelas XI IPS 2 di SMA Negeri 6 Merangin belum mampu untuk mencari sumber belajar mandiri yang benar-benar relevan, siswa masih memerlukan bimbingan guru ketika ingin belajar. Salah satu sumber belajar yang bisa untuk memecahkan permasalahan ini adalah elektronik modul ( $e$ modul).

E-modul merupakan bahan ajar yang disusun secara terstruktur berasarkan kurikulum tertentu dan dikemas pada waktu tertentu, yang ditampilkan menggunakan alat elektronik seperti komputer atau smartphone (Purmadi \& Surjono, 2016). Dalam e-modul pembelajaran berisi materi, metode, batasan-batasan, dan cara mengevaluasi yang dirancang secara sistematis dan menarik untuk mencapai kompetensi yang diharapkan sesuai dengan tingkat kompleksitasnya secara elektronik (Cheva \& Zainul, 2019). Tujuan dari dibuatnya e-modul pembelajaran yaitu agar guru dan siswa: (a) dapat memperjelas dan mempermudah penyajian pesan agar tidak terlalu bersifat verbal; (b) untuk mengatasi keterbatasan waktu, ruang, dan daya indera; (c) secara tepat dan bervariasi meningkatkan motivasi serta gairah belajar; (d) memungkinkan belajar mandiri sesuai kemampuan dan minatnya; (e) dapat mengukur dan mengevaluasi sendiri proses dan output pembelajarannya (Lumbantobing, Munadi, \& Wijanarka, 2019). 
Kelebihan pada e-modul dari modul yang tersedia versi cetak adalah sifatnya yang memudahkan pada navigasi, memungkinkan untuk menampilkan/memuat gambar, audio, dan animasi serta dilengkapi soal, kuis dan penilaian formatif lainnya yang memungkinkan umpan balik otomatis dengan segera (Sugihartini \& Jayanta, 2017). Struktur penulisan e-modul pada dasarnya pada mengadaptasi format, karakteristik, dan bagian-bagian yang terdapat pada modul cetak pada umumnya, amun terdapat beberapa perbedaan. Perbedaan antara modul cetak dan e-modul dapat dilihat pada tabel di bawah ini.

Tabel 1. Perbedaan Modul cetak dan E-Modul

\begin{tabular}{l|l}
\hline \multicolumn{1}{c|}{ E-Modul } & \multicolumn{1}{c}{ Modul Cetak } \\
\hline $\begin{array}{l}\text { Format pada } e \text {-modul berupa (file, doc, } p d f \text {, exe, } \\
\text { Swf, dll) }\end{array}$ & Format berbentuk cetak atau kertas \\
\hline $\begin{array}{l}\text { ditampilkan menggunakan perangkat elektronik } \\
\text { dan Sofware khusus (laptop, PC, HP, Internet) }\end{array}$ & $\begin{array}{l}\text { Tampilannya berupa kumpulan kertas yang } \\
\text { tercetak. }\end{array}$ \\
\hline Lebih praktis untuk dibawa & $\begin{array}{l}\text { Berbentuk fisik dan untuk membawa } \\
\text { dibutuhkan ruang untuk meletakkannya. }\end{array}$ \\
\hline Biaya produksi lebih murah & Biaya produksi lebih mahal \\
\hline Tahan lama dan tidak lapuk dimakan waktu & Daya tahan kertas terbatas oleh waktu \\
\hline Perlu sumber tenaga listrik & $\begin{array}{l}\text { Tidak perlu sumber daya khusus untuk } \\
\text { menggunakannya }\end{array}$ \\
\hline
\end{tabular}

Sumber: Data Primer (2021)

Berdasarkan penjelasan di atas dapat disimpulkan bahwa e-modul ialah modul pembelajaran yang dapat ditampilkan dengan menggunakan media elektronik dengan menggunakan software khusus seperti, PC, laptop, handphone maupun internet tetapi tidak menghilangkan keraktreristik dan bagianbagian yang terdapat pada modul cetak yang ada pada umumnya (Khairoes \& Taufina, 2019).

Tujuan dari dibuatnya e-modul pembelajaran yaitu: (a) dapat memperjelas dan mempermudah penyajian pesan agar tidak terlalu bersifat verbal; (b) untuk mengatasi keterbatasan waktu, ruang, dan daya indera, baik siswa atau maupun guru; (c) digunakan secara tepat dan bervariasi, seperti untuk meningkatkan motivasi serta gairah belajar bagi siswa yang menggunakanya, memungkinkan untuk belajar mandiri sesuai kemampuan dan minatnya, memungkinkan dapat mengukur dan mengevaluasi sendiri hasil belajarnya (Lumbantobing et al., 2019). E-modul yang digunakan yaitu e-modul berbasis anyflip yang digunakan melalui smartphone atau laptop. Penggunaan pada e-modul ini tidak dibatasi oleh tempat dan waktu, tergantung sarana dan prasarana yang dimiliki siswa dalam mengakses e-modul tersebut. Pengembangan sumber belajar untuk siswa perlu dilakukan guru sebagai bentuk usaha guru dalam inovasi dalam pembelajaran dan meningkatkan kompetensi siswa (Anisah \& Azizah, 2016). E-modul ini sangat berperan penting dalam membantu pembelajaran di sekolah karena dapat digunakan sebagai alat membantu guru dalam kegiatan pembelajaran. Penelitian ini bertujuan untuk melihat keefektifan e-modul berbasis anyflip untuk meningkatkan pemahaman materi pada siswa.

\section{Metode Penelitian}

Metode pada penelitian ini menggunakan pendekatan kuantitatif dan tipe penelitian eksperimen dengan rancangan penelitian one group pretest-posttest design. Desain ini memberikan kesempatan kepada peneliti untuk mengetahui efektivitas penggunaan e-modul berbasis anyflip terhadap hasil belajar siswa. Penelitan ini menggunakan satu kelas uji coba, diawali dengan tes awal (pretest) pada kelas eksperimen untuk mengetahui kemampuan awal siswa pada materi integrasi sosial. Hasil dari prettest kelas tersebut kemudian diolah untuk mendapatkan hasil rata-

Jurnal Sikola: Jurnal Kajian Pendidikan dan Pembelajaran Vol. 3, No. 2, Th. 2021 
rata nilai yang dicapai oleh siswa. Pada tahap berikutnya peneliti menerapkan pembelajaran menggunakan bantuan e-modul yang telah dirancang. Setelah pembelajaran pada kelas ekperimen selesai, siswa diberikan evaluasi akhir (posttest), kemudian skor pretest dan posttest dari kelas eksperimen dibandingkan, agar dapat mengetahui perbedaan hasil pembelajaran antara sebelum dan sesudah pemberian pada e-modul. Teknik pengumpulan data dilakukan dengan pemberian soal tes pada siswa. Soal yang diberikan berjenis pilihan ganda yang terdiri dari 20 soal yang akan menguji penguasan materi integrasi sosial. Pengumpulan data berupa instrumen yang berbentuk soal yang digunakan pada saat pretest dan posttest. Sampel pada penelitian ini adalah 31 orang siswa kelas XI IPS 2 di SMA Negeri 6 Merangin. Untuk melakukan analisis data pada efektivitas e-modul berbasis anyflip, terlebih dahulu dilakukan uji coba normalitas dan homogenitas data dari skor pretest dan posttest siwa. Selanjutnya uji hipotesis berdasarkan skor prettest dan posttest siswa dengan menggunakan formula rumus uji t (t-test) untuk mengetahui efektivitas e-modul berbasis anyflip yang digunakan siswa dalam proses pembelajaran di Kelas XI IPS 2 SMA Negeri 6 Merangin.

\section{Hasil dan Pembahasan}

Penelitian ini bertujuan untuk menguji efektifitas penggunaan e-modul pembelajaran sosiologi berbasis any anyflip pada siswa kelas XI IPS 2 di SMA Negeri 6 Merangin. Berikut adalah contoh desain e-modul berbasis anyflip yang telah dikembangkan dan diujicobakan.

Tabel 2. Desain E-modul Sosiologi Berbasis Anyflip

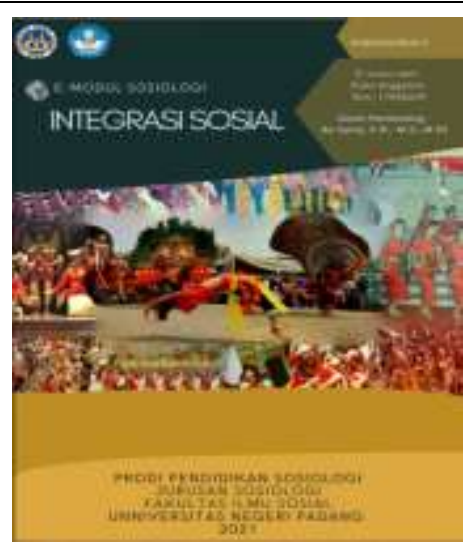

Cover pada e-modul

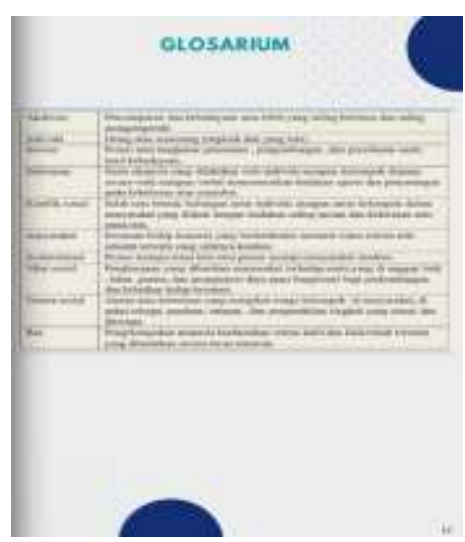

Glosarium pada e-modul

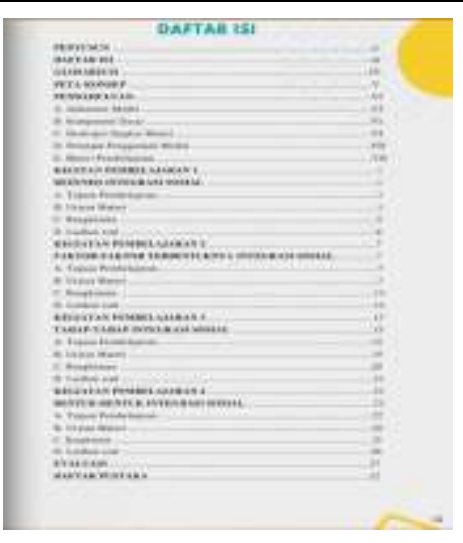

Daftar isi pada e-modul

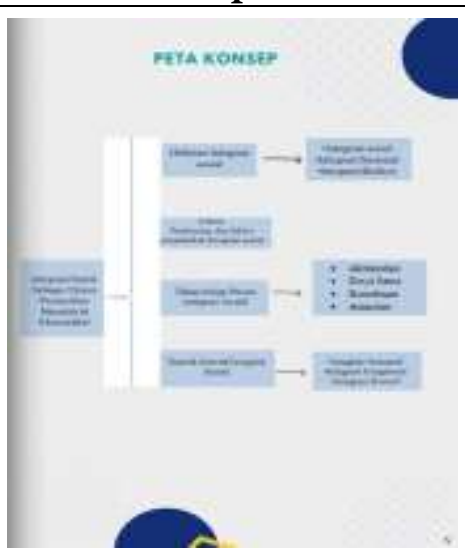

Peta konsep pada e-modul

Jurnal Sikola: Jurnal Kajian Pendidikan dan Pembelajaran Vol. 3, No. 2, Th. 2021 


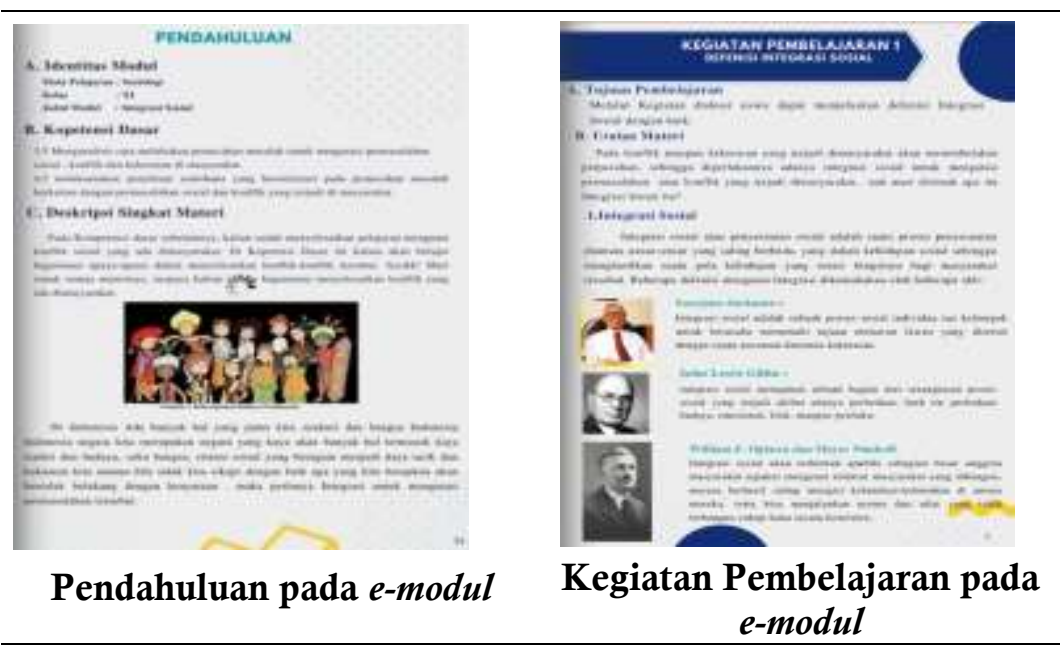

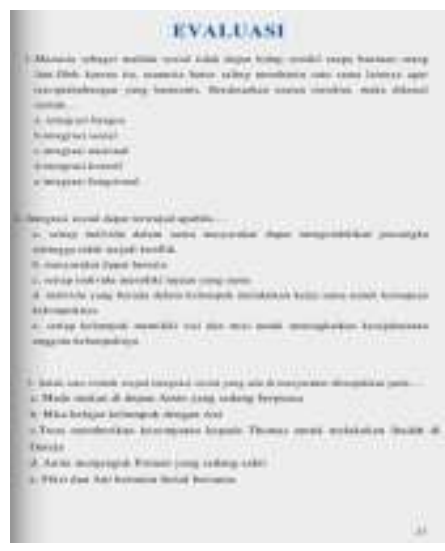

Evaluasi pada $e$-modul

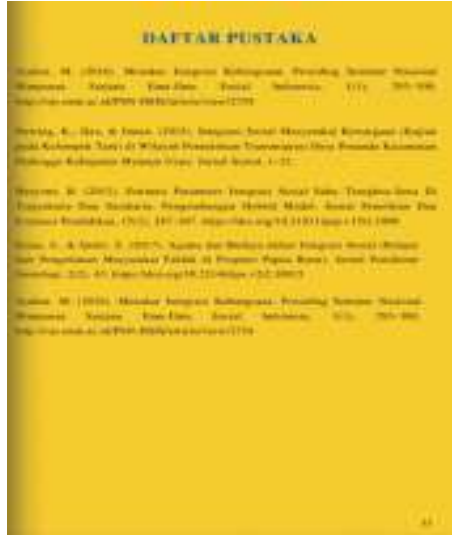

Daftar Pustaka pada e-modul

Kompoenen e-modul yang telah dirancang berisi daftar isi, peta konsep, pendahuluan, materi pembelajaran serta evaluasi dan glosarium. E-modul ini digunakan sebagai alat untuk melengkapi bahan ajar yang digunakan oleh guru dalam proses pembelajaran. E-modul sangat efektif dalam membantu siswa untuk belajar secara mandiri baik di sekolah maupun di rumah dan siswa dapat mengukur tingkat pemahamannya sendiri (Natalia, Maridi, \& Suciati, 2016).

Efektivitas pada dasarnya ialah dampak yang timbul dari suatu tindakan. Pada penelitian ini efektifitas dimaknai sebagai dampak pada penggunaan e-modul terhadap hasil belajar siswa. Untuk membuktikan efektivitas, digunakan uji statistik untuk mengetahui tingkat keberhasilan produk pada kegiatan pembelajaran. E-modul bisa dikatakan efektif apabila e-modul tersebut bisa memberikan dampak meningkatnya hasil belajar siswa setelah menggunakan e-modul. Produk pembelajaran yang telah dikembangkan sebelumnya, terlebih dahulu diuji validasi oleh ahli dan diketahui reliabilitasnya.

Pada penelitian ini yang diteliti yaitu hasil belajar berupa nilai prettest dan possttest dan ketuntasan hasil belajar. Soal diberikan kepada siswa di kelas XI IPS 2 SMA Negeri 6 Merangin terdiri dari 20 soal pilihan ganda dengan siswa berjumlah 31 orang. Skor pretest akan dibandingkan dengan hasil posttest sehingga dapat mengetahui apakah kegiatan belajar mengajar tersebut berhasil baik atau tidak serta diharapkan pemahaman siswa lebih baik terhadap materi yang diberikan dan memotivasi siswa untuk lebih serius dalam memperhatikan pembelajaran 
sehingga dapat menigkatkan hasil belajar siswa. Berikut ini adalah kisi-kisi soal yang digunakan dalam pretest dan posttest.

Tabel 3. Kisi-Kisi Soal Pretest-Posttest

\begin{tabular}{llcc}
\hline No & \multicolumn{1}{c}{ Indikator Soal } & Tipe Soal & No Soal Objektif \\
\hline 1 & $\begin{array}{l}\text { Menjelaskan pengertian integrasi dan } \\
\text { integrasi sosial }\end{array}$ & C2 & $1,2,4,15$ \\
\hline 2 & $\begin{array}{l}\text { Memberikan contoh dari integrasi } \\
\text { sosial }\end{array}$ & C2 & $3,19,8,13$ \\
\hline 3 & $\begin{array}{l}\text { Mengelompokkan bentuk-bentuk dari } \\
\text { integrasi sosial }\end{array}$ & $\mathrm{C} 4$ & $5,12,17$ \\
\hline 4 & $\begin{array}{l}\text { Menentukan tahap dan proses } \\
\text { terbentuknya integrasi sosial }\end{array}$ & $\mathrm{C} 4$ & $6,9,10,11,14,16$ \\
\hline 5 & $\begin{array}{l}\text { Menentukan fungsi dari Integrasi } \\
\text { Sosial }\end{array}$ & $\mathrm{C} 4$ & $7,18,20$ \\
\hline & \multicolumn{3}{l}{ Jumlah Soal } \\
\hline
\end{tabular}

Sumber: Data Primer 2021

Setelah melakukan penelitian dan memberikan soal prettest dan posttest maka diperoleh hasil rekapitulasi nilai data pretest dan posttest siswa kelas XI IPS 2 SMA Negeri 6 Merangin yang dapat dilihat pada gambar 3 di bawah ini.

\section{Gambar 3. Rekapitulasi Hasil Data Pretest dan Posttest Siswa kelas XI IPS 2 SMA Negeri 6 Merangin}

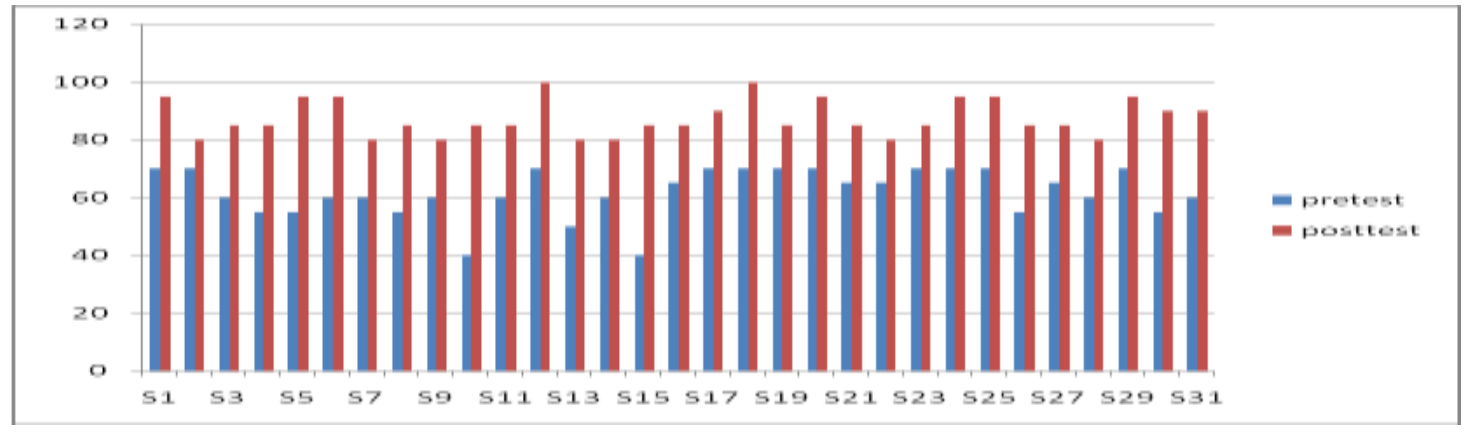

Sumber: Data Primer 2021

Hasil dari diagram batang di atas memperlihatkan bahwa nilai posttest 31 orang siswa lebih tinggi dibandingkan dengan nilai pada pretest. Selanjutnya hasil skor prettest dan posttest siswa terlebih dahulu diuji normalitas dan homogenitasnya. Uji normalitas yang digunakan untuk melihat normal atau tidak normalnya data dan uji homogenitas digunakan untuk melihat varian data.

\section{Uji Normalitas Kolmogrov Smirnov}

Uji normalitas merupakan suatu tahapan yang digunakan untuk mengetahui apakah data berasal dari populasi yang berdistribusi normal atau hanya berada dalam sebaran normal. Uji normalitas memiliki tujuan mengetahui apakah ada nilai residual yang berdistribusi normal atau tidak. Uji kolmogorov smirnov termasuk bagian dari uji asumsi klasik. Uji Kolmogorov Smirnov merupakan pengujian normalitas yang sering dipakai, terutama setelah adanya banyak program 
statistik yang beredar (Quraisy, 2020). Dasar dari pengambilan keputusan adalah jika nilai signifikansi $>0,05$, maka nilai residual berdistribusi normal dan jika signifikansi $<0,05$, maka nilai residual tidak berdistribusi normal. Berikut hasil uji normalitas dapat dilihat pada tabel 5.

Tabel 4. Hasil Analisis UJi Normalitas One-Sample Kolmogorov-Smirnov Test

\begin{tabular}{lll}
\hline $\mathrm{N}$ & & 31 \\
\hline Normal Parameters & & \\
& Mean & .0000000 \\
\cline { 2 - 3 } Most Extreme Differences & Std. Deviation & 5.83023673 \\
\cline { 2 - 3 } & Absolute & .121 \\
\cline { 2 - 3 } & Positive & .113 \\
\cline { 2 - 3 } Negative & -.121 \\
\hline Test Statistic & & .121 \\
\hline
\end{tabular}

Sumber: Data Primer (2021)

Berdasarkan hasil uji normalitas menggunakan formula One Sample Kolmogorov-Smirnov Test menunjukkan nilai signifikansi $0,121>0,05$, artinya nilai residual berdistribusi normal, maka selanjutnya dapat dilanjutkan dengan uji homogenitas.

\section{Uji Homogenitas}

Konsep dasar uji homogenitas merupakan suatu uji yang dilakukan untuk mengetahui bahwa dua atau lebih kelompok data sampel berasal dari populasi yang memiliki varians yang sama atau homogen (Wiliawanto, Bernard, Akbar, \& Sugandi, 2019). Pengujian ini merupakan persyaratan sebelum melakukan uji hipotesis. Pengujian ini digunakan untuk meyakinkan bahwa kelompok data memang berasal dari populasi yang memiliki varians yang sama (homogen). Dasar dari pengambilan keputusan untuk uji homogenitas ini jika nilai signifikansi $>0,05$, maka distribusi data homogen dan jika nilai signifikansi $<0,05$, maka distribusi data tidak homogen. Berikut hasil analisis uji pada homogenitas data kelas XI IPS 2 disajikan pada tabel 5 berikut ini:

Tabel 5. Hasil Analisis Uji Homogenitas Test of Homogeneity of Variances

\begin{tabular}{|c|c|c|c|c|c|}
\hline & & $\begin{array}{l}\text { Levene } \\
\text { Statistic }\end{array}$ & $d f 1$ & $d f 2$ & Sig. \\
\hline Hasil Belajar & Based on Mean & 1.407 & 1 & 60 & .240 \\
\hline \multirow[t]{3}{*}{ Sosiologi } & Based on Median & 1.897 & 1 & 60 & .174 \\
\hline & $\begin{array}{l}\text { Based on Median and } \\
\text { with adjusted df }\end{array}$ & 1.897 & 1 & 59.056 & .174 \\
\hline & Based on trimmed mean & 1.560 & 1 & 60 & .217 \\
\hline
\end{tabular}

Sumber: Data Primer (2021)

Acuan yang digunakan untuk menginterpretasikan data diatas adalah jika nilai pada signifikansi $>0,05$, dapat dikatakan data berdistribusi homogen dan jika nilai signifikansi $<0,05$ maka data tidak homogen. Pada tabel 5 diatas dapat dilihat nilai signifikansi $>0,05$ sehingga data skor pretest dan posttest memiliki varians yang sama atau homogen, sehingga selanjutnya dapat dilanjutkan dengan pengujian hipotesis. 


\section{Uji Hipotesis Paired samples Test}

Analisis uji t berpasangan (paired sample test) digunakan sebagai alat pengujian hipotesis (Yusuf, 2016). Uji T dua sampel yang berpasangan merupakan uji sampel dengan subyek yang sama namun mengalami dua perlakuan atau pengukuran yang berbeda (Satyahadewi \& Perdana, 2021). Untuk mengambil keputusan dalam uji ini jika nilai signifikansi (2-tailed) $<0,05$ menunjukan adanya perbedaan yang singnifikan antara variabel awal dengan variabel akhir. Ini menunjukan terdapat pengaruh yang bermakna terhadap perbedaan yang diberikan pada masing-masing variabel. Dan jika signifikansi (2-tailed) $>0,05$ menunjukan tidak terdapat perbedaan yang signifikan antara variabel awal dengan variabel akhir. Ini menunjukan tidak terdapat pengaruh yang bermakna terhadap perbedaan perlakukan yang diberikan. Berikut hasil analisis uji hipotesis:

Tabel 6. Hasil Analisis Uji Hipotesis Paired Samples Test

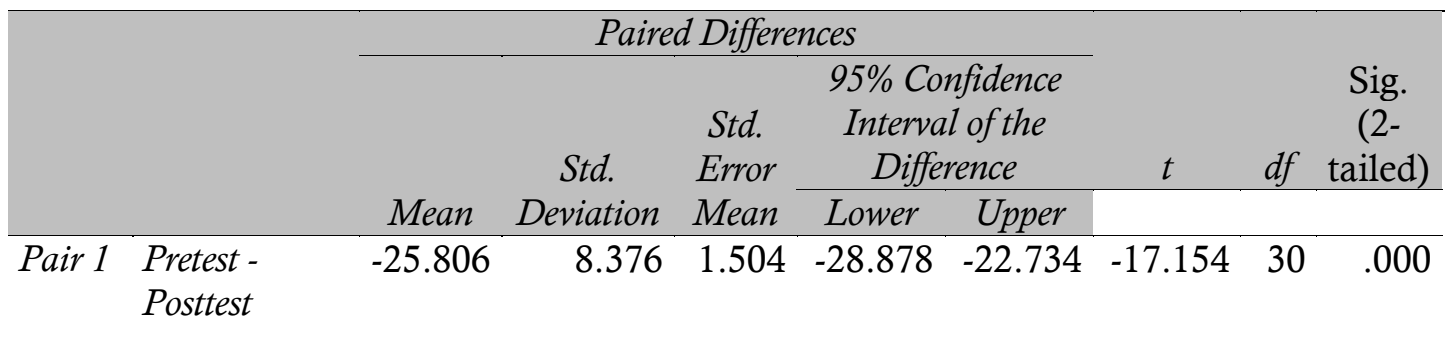

\section{Sumber: Data Primer (2021)}

Nilai signifikansi yang terdapat di tabel 6 sebesar $0,000 \quad(0,000<0,05)$ yang dapat disimpulkan bahwa terdapat perbedaan yang signifikan hasil belajar siswa kelas XI IPS 2 SMA Negeri 6 Merangin sebelum dan sesudah diberikanya perlakuan yaitu e-modul pada pembelajaran sosiologi berbasis anyflip. Hasil ini memperlihatkan bahwa terdapat pengaruh penggunaan $e$ modul berbasis anyflip pada pembelajaran sosiologi SMA kelas XI IPS 2 pada materi integrasi sosial terhadap hasil belajar mereka. Artinya penggunaan pada e-modul berbasis anyflip pada pembelajaran sosiologi SMA kelas XI IPS 2 materi integrasi sosial efektif dan mampu meningkatkan hasil belajar siswa di kelas XI IPS 2 SMA Negeri 6 Merangin, khususnya pada materi integrasi sosial. Siswa pada kelas XI IPS 2 di SMA Negeri 6 Merangin yang belajar melalui e-modul berbasis anyflip dapat terbantu selama proses pembelajaran pada saat pademi covid-19 ini, karena e-modul ini dapat membuat siswa untuk belajar secara mandiri.

Pembelajaran yang efektif adalah pembelajaran yang mampu mencapai target yang diinginkan, baik berdasarkan pada tujuan pembelajaran juga tingkat prestasi siswa yang maksimal. Adapun beberapa indikator keefektifan pada pembelajaran, yaitu tercapainya ketuntasan dalam belajar, aktivitas siswa yang diharapkan, kemapuan pada guru mengelola pembelajaran, serta respon siswa terhadap pembelajaran yang positif (Pane \& Darwis Dasopang, 2017). Efektivitas pembelajaran ini sebuah tingkat pada keberhasilan yang ingin dicapai berdasarkan suatu metode pembelajaran yang bersinergi dengan tujuan pembelajaran yang sudah direncanakan sebelumnya. Pada penelitian ini e-modul yang diimplementasikan dalam pembelajaran materi integrasi sosial memuat langkah-langkah pembelajaran sesuai dengan model pembelajaran yang dirancang oleh guru. Kelebihan yang dimiliki oleh e-modul ini antara lain adalah : peserta didik memiliki pengetahuan awal dari peta konsep dan fenomena yang disajikan pada bagian awal e-modul, sehingga siswa dapat memahami terlebih dahulu materi yang akan dipelajari, membangun rasa ingin tahu dan muncul motivasi siswa untuk mengetahui lebih dalam mengenai materi sehingga siswa berusaha membuat koneksi tentang pengetahuan sebelumnya dengan pengetahuan yang dipelajari. (Santika \& Sylvia, 2021). Bahan ajar dalam bentuk e-modul yang disusun secara secara sistematik dan terstrutur, dapat membantu 
tercapainya tujuan pembelajaran, memotivasi siswa, mengatasi kesulitan pada saat pembelajaran, memberikan latihan dan rangkuman, serta berorientasi pada kegiatan belajar mandiri bagi siswa (Rizqi \& Kusumo, 2016).

\section{Kesimpulan}

Penelitian ini sudah menghasilkan sebuah produk yaitu e-modul pada pembelajaran sosiologi berbasis anyflip yang mampu membantu siswa dalam proses pembelajaran. E-modul berbasis anyflip tersebut sudah teruji efektif digunakan untuk siswa karena sudah sesuai dengan hasil pengujian empiris. Kajian empiris telah dilakukan melalui pembelajaran yang mengintegrasikan e-modul pada materi integrasi sosial di kelas XI IPS 2 telah terbukti efektif berpengaruh terhadap hasil belajar siswa, dengan hasil uji hipotesis menggunakan rumus uji $\mathrm{t}$ dan rata-rata skor postteset lebih tinggi dari pada skor rata-rata pretset. Hal ini disebabkan karena e-modul disususn secara sistematis, terstruktur, dilengkapi dengan peta konsep, materi, fenomena kontekstual dan uji formatif yang dapat memacu motivasi dan keinginan siswa untuk belajar secara mandiri.

\section{Daftar Pustaka}

Anisah, A., \& Azizah, E. N. (2016). Pengaruh Penggunaan Buku Teks Pelajaran dan Internet Sebagai Sumber Belajar Terhadap Hasil Belajar Siswa Pada Pembelajaran IPS (Eksperimen Kuasi Pada Kelas VII di SMP Negeri 1 Palimanan Kabupaten Cirebon). Jurnal Logika, 18(3), 1-18.

Arsal, M., Danial, M., \& Hala, Y. (2019). Pengembangan Media Pembelajaran E-Modul Materi Sistem Peredaran Darah Pada Kelas XI MIPA SMAN 6 BARRU. Prosiding Seminar Nasional Biologi VI, 434-442.

Cheva, V. K., \& Zainul, R. (2019). Pengembangan E-Modul Berbasis Inkuiri Terbimbing Pada Materi Sifat Keperiodikan Unsur untuk SMA/MA Kelas X. EduKimia, 1(1). https://doi.org/10.24036/ekj.v1i1.104077

Khairoes, D., \& Taufina, T. (2019). Peneran Story Telling untuk Meningkatkan Keterampilan Berbicara di Sekolah Dasar. Jurnal Basicedu, 3(4), 1038-1046. https://doi.org/10.31004/basicedu.v3i4.220

Lumbantobing, M. A., Munadi, S., \& Wijanarka, B. S. (2019). Pengembangan E-Modul Interaktif untuk Discovery Learning pada Pembelajaran Mekanika Teknik dan Elemen Mesin. Jumal Dinamika Vokasional Teknik Mesin, 4(1), 1-8. https://doi.org/10.21831/dinamika.v4i1.24275

Natalia, P., Maridi, M., \& Suciati, S. (2016). Pengembangan Modul Berbasis Guided Inquiry Laboratory Untuk Meningkatkan Literasi Sains Dimensi Proses Materi Sistem Pencernaan Pada Kelas Xi. Inkuiri, 5(2), 52-63.

Pane, A., \& Darwis Dasopang, M. (2017). Belajar dan Pembelajaran. FITRAH: Jurnal Kajian Ilmu-Ilmu Keislaman, 3(2), 333. https://doi.org/10.24952/fitrah.v3i2.945

Purmadi, A., \& Surjono, H. D. (2016). Pengembangan Bahan Ajar Berbasis Web Berdasarkan Gaya Belajar Siswa Untuk Mata Pelajaran Fisika. Jurnal Inovasi Teknologi Pendidikan, 3(2), 151. https://doi.org/10.21831/jitp.v3i2.8285

Quraisy, A. (2020). Normalitas Data Menggunakan Uji Kolmogorov-Smirnov dan SaphiroWilk. J-HEST: Journal of Healt, Education, Economics, Science, and Technology, 3(1), 7-11.

Rizqi, T., \& Kusumo, E. (2016). Penerapan Model Pembelajaran Konstruktivisme Berbantuan Concept Map untuk Meningkatkan Hasil Belajar Kimia Pada Siswa SMA. Jurnal Inovasi Pendidikan Kimia, 6(2), 1093-1102. 
Santika, A., \& Sylvia, I. (2021). Efektivitas E-Modul Berbasis Anyflip untuk Meningkatkan Kemampuan Penguasaan Materi Peserta Didik pada Materi Nilai dan Norma Sosial Kelas X di SMA N 3 Payakumbuh. Jurnal Sikola: Jurnal Kajian Pendidikan Dan Pembelajaran, 2(4), 285-296. https://doi.org/10.24036/sikola.v2i4.128

Satyahadewi, N., \& Perdana, H. (2021). Pengembangan Aplikasi Statistika Berbasis Web Interaktif Untuk Analisis Uji- T. 10(3), 331-340.

Solihudin JH, T. (2018). Pengembangan E-Modul Berbasis Web untuk Meningkatkan Pencapaian Kompetensi Pengetahuan Fisika Pada Materi Listrik Statis dan Dinamis SMA. WaPFi (Wahana Pendidikan Fisika), 3(2), 51. https://doi.org/10.17509/wapfi.v3i2.13731

Sudarsana, I. K. (2018). Optimalisasi Penggunaan Teknologi dalam Implementasi Kurikulum di Sekolah (Persepektif Teori Konstruktivisme). Cetta: Jurnal Ilmu Pendidikan, 1(1), 8-15.

Sugihartini, N., \& Jayanta, N. L. (2017). Pengembangan E-Modul Mata Kuliah Strategi Pembelajaran. Jurnal Pendidikan Teknologi Dan Kejuruan, 14(2), 221-230. https://doi.org/10.23887/jptk-undiksha.v14i2.11830

Wiliawanto, W., Bernard, M., Akbar, P., \& Sugandi, A. I. (2019). Penerapan Strategi Pembelajaran Aktif Question Student Have Untuk Meningkatkan Kemampuan Berpikir Kritis Matematik Siswa SMK. Jurnal Cendekia: Jurnal Pendidikan Matematika, 3(1), 139148. https://doi.org/10.31004/cendekia.v3i1.86

Yusuf, A.M. (2016). Metode Penelitian Kuantitatif, Kualitatif \& Penelitian Gabungan. Jakarta: Prenada Media. 